\title{
CHRONOLOGIA PÓŹNYCH FAZ \\ KULTURY DNIEPRO-DONIECKIEJ NA BIALORUSI \\ W ŚWIETLE NAJNOWSZYCH OZNACZEŃ RADIOWĘLOWYCH \\ ZE STANOWISKA PRORVA 2, REJON ROGACZOWSKI
}

\author{
CHRONOLOGY OF THE LATE PHASES OF THE DNIEPR-DONETZ \\ CULTURE IN BYELORUSSIA IN THE LIGHT OF THE NEWEST \\ RADIOCARBON DATES FROM PRORVA, SITE 2, THE ROGACZÓW REGION
}

Igor Jaziepienko

Instytut Historii Narodowej Akademii Nauk ul. Akademiczna 1, 220007 Mińsk, Białoruś

\author{
Bartosz Jóźwiak \\ Instytut Prahistorii, Uniwersytet im. Adama Mickiewicza \\ ul. Św. Marcin 78, 61-809 Poznań, Polska
}

ABSTRACT. The paper presents an analysis of the newest radiocarbon dates from Prorva, site 2 in the Rogaczów region. It provides a basis for the chronological studies of the Dnieper-Donetz culture in Byelorussia.

\section{WSTEPP}

Najwcześniejsze odkrycia wiązane z kulturą dniepro-doniecką pochodzą z lat 20 . i 30. XX w. z Nadporoża. Sama zaś jednostka kulturowa wydzielona została ostatecznie na przełomie lat 50. i 60 . przez D.J. Telegina, głównie na podstawie materiałów ukraińskich'. W wyniku tych studiów ustalono wstępną (opartą na cechach typologicznych) chronologię - z czasem uzupełnioną datami radiowęglowymi z terenu Ukrainy - oraz zasięg terytorialny i zróżnicowanie wewnętrzne omawianego zjawiska.

Dziś dość powszechnie uznaje się, iż omawianą - bardzo złożoną wewnętrznie strukturę należy traktować jako rodzaj swoistej wspólnoty kulturowej, czy nawet wspólnoty etnokulturowej (tzw. dniepro-doniecka etnokulturnaja obszcznost ${ }^{2}$ ). Wspólnota ta miałaby powstać w rejonie Naddnieprza, Polesia i lasostepowej części prawobrzeża

\footnotetext{
'Telegin 1961; 1967; 1968; Archieologia 1985, s. 156-158.

${ }^{2}$ Telegin, Titova 1998; Telegin 1999.
} 
Dniepru na podstawie miejscowych ugrupowań mezolitycznych, które pod wpływem impulsów ze środowiska kultury boho-dniestrowskiej, przyswoily sobie umiejętność wyrobu ostrodennych naczyń ceramicznych oraz niektórych nowych form narzędzi krzemiennych ${ }^{3}$. Tym samym powinna ona stanowić kolejne ogniwo zachodniego szlaku dyfuzji ceramiki subneolitycznej, współtworząc jednocześnie tzw. krag kultur z ceramiką grzebykowo-nakłuwaną ${ }^{4}$. Chronologicznie ogół struktur „dniepro-donieckich” można podzielić na trzy zasadnicze etapy: wczesny (5500-4800 p.n.e.), środkowy (4800-3800 p.n.e. - na terenie białoruskiej części dorzecza Prypeci do około 3500 p.n.e.) i późny (3800-3000 p.n.e. - na Ukrainie oraz od około 3500 do co najmniej, jak się dotychczas wydawało, połowy II tys. p.n.e. na terenie Białorusi $)^{5}$.

$\mathrm{Na}$ interesującym nas w tym artykule obszarze Białorusi wspólnota dniepro-doniecka pojawia się już we wczesnym etapie (I etap według systematyki białoruskiej) swojego rozwoju i zajmuje obszar wschodniego Polesia oraz dorzecze Dniepru - gdzie wcześniej wydzielano tylko kulturę górnowołżańską - aż po linię Bobrujsk-Rogaczow na północy ${ }^{6}$. Na etapie środkowym (II etap) dochodzi do rozbicia jednolitej dotychczas struktury dniepro-donieckiej na szereg grup/kultur regionalnych, co inicjuje polilinearny etap rozwoju omawianego zjawiska ${ }^{7}$. Na terenie Białorusi rozpoczyna się wtedy okres rozwoju grupy/kultury wschodniopoleskiej ${ }^{8}$. Nieco bardziej zlożony jest obraz rozwoju w późnym etapie omawianych zjawisk. Otóż na terenie Ukrainy dochodzi, pod wpływem kultury trypolskiej i kultury jamkowo-grzebykowej, do stopniowego zaniku dniepro-donieckich struktur regionalnych - tylko niektóre z nich rozwijają się jeszcze na tym etapie - oraz tworzenia się ugrupowań o złożonej charakterystyce genetycznej (typ Zasuchy, typ Pustynka), powstałych wskutek asymilacji w środowisku dniepro-donieckim szeregu cech obcych kulturowo (np. kultury trypolskiej) ${ }^{9}$. Jednocześnie na obszarze Białorusi nadal rozwija się wariant wschodniopoleski omawianej wspólnoty. Wówczas można wydzielić w jego rozwoju dwa etapy: III oraz IV - w którym w ceramice dniepro-donieckiej zaznaczają się wyraźniejsze wpływy kultur sąsiednich (np. kultury środkowodnieprzańskiej czy kultury górnowołżańskiej) ${ }^{10}$. Finał procesu dezintegracji omawianej grupy/kultury sytuowano dotychczas w połowie II tysiąclecia, jednak brak oznaczeń radiowęglowych nie pozwalał na wyznaczenie dokladniejszej daty tego zjawiska ${ }^{11}$.

Jak wynika z powyższych uwag, na obszarze Ukrainy pozyskano pewną ilość oznaczeń radiowęglowych, które pozwoliły ustalić przynajmniej wstępną chronologię bezwzględną zjawisk dniepro-donieckich na tym terenie; obszar Białorusi natomiast był dotychczas pozbawiony takowych ustaleń. Częściowo wynikało to ze specyfiki osadniczej,

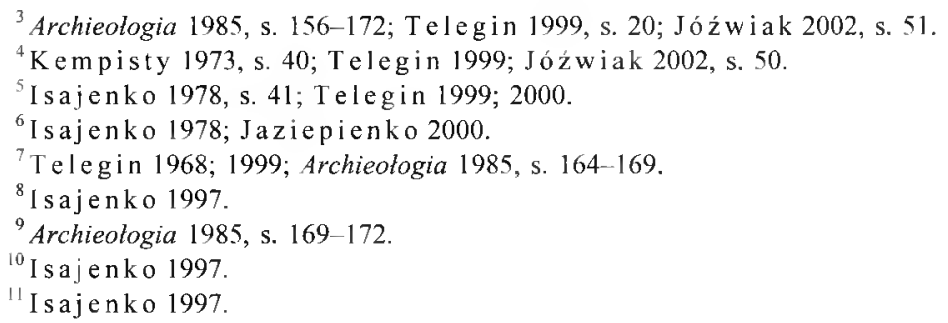


która wyraźnie wiązała osadnictwo dniepro-donieckie z obszarami gleb lekkich (głównie wydm), w zasadzie nie dających możliwości zachowania się, niezbędnego do datowań, materiału organicznego. Impas ten udało się przełamać dopiero w ostatnich latach, kiedy w celu poddania analizie radiowęglowej, wydzielono z ogółu zbiorów ceramikę ze śladami nagarów, pozyskaną w trakcie prac prowadzonych w dorzeczu Dniepru, na stanowisku Prorva $2^{12}$.

\section{OPIS POLOŻENIA STANOWISKA PRORVA 2 I PROWADZONYCH NA NIM BADAŃ}

Wielokulturowe stanowisko Prorva 2 było badane w latach 1994-1996 oraz w roku 1998 przez ekspedycję Instytutu Historii Narodowej Akademii Nauk Białorusi pod kierownictwem mgr. Igora Jaziepienko. W wyniku prac terenowych pozyskano materiał źródłowy związany z interesującym nas okresem, w postaci 2203 zabytków krzemiennych (w tym 405 ze śladami retuszowania), 8424 fragmentów ceramiki naczyniowej z III i IV etapu rozwoju grupy/kultury wschodniopoleskiej wspólnoty dniepro-donieckiej, 2054 fragmentów ceramiki naczyniowej z wczesnej epoki brązu (według periodyzacji białoruskiej) oraz łączony z tym etapem zasiedlenia pochówek kultury środkowodnieprzańskiej, z jej środkowej fazy rozwojowej ${ }^{13}$.

Stanowisko położone jest na wydmie o powierzchni $2400 \mathrm{~m}^{2}$, leżącej w centrum lewobrzeżnej części doliny Dniepru, na północnym skraju Równiny Naddnieprowskiej (ryc. 1). W obrębie pięciu wykopów o łącznej powierzchni $341 \mathrm{~m}^{2}$ objęto badaniami głównie najwyżej położoną część stanowiska $(0,9 \mathrm{~m}-1,6 \mathrm{~m}$ nad poziomem terasy rzecznej) (ryc. 2). Materiał źródłowy zalegał w warstwie o miąższości $55 \mathrm{~cm}-60 \mathrm{~cm}$.

\section{CHARAKTERYSTYKA TECHNOSTYLISTYCZNA CERAMIKI PODDANEJ ANALIZIE}

Dla potrzeb chronologii radiowęglowej wybrano sześć fragmentów ceramiki naczyniowej ze śladami nagarów (ryc. 3), przy czym dwa z nich pochodziły z tego samego naczynia (ryc. 3:2, 3:3). Próby przekazano do Laboratorium Radiowęglowego w Kijowie w dwóch niezależnych seriach. Dwa fragmenty pochodzące z badań w 1995 r. (Ki-6590 oraz Ki-7519) zostały przesłane do datowania nieco wcześniej (przez I. Jaziepienko) i na ich wyniki powoływano się już w niektórych publikacjach ${ }^{14}$. Pozostałe cztery próby nie były jeszcze dotychczas publikowane i tym samym wymagają szerszego omówienia.

Próba Ki-9280 to nieornamentowany fragment brzuśca typowego, ostrodennego garnka dniepro-donieckiego. Masa ceramiczna była w tym przypadku schudzona znaczną ilością włóknistej domieszki roślinnej i różnobarwnego tłucznia kamiennego o różnej granulacji. Przełam fragmentu był gruzełkowaty (masa ceramiczna słabo wy-

\footnotetext{
${ }^{12}$ Jaziepienko $1994 ; 1995 ; 2000 a ; 2000 b$.

${ }^{13}$ Kryvalsevicz, Kovaliuch 1999; Jaziepienko 2000 a.

${ }^{14} \mathrm{~J}$ aziepienk o 2000a; Jóźwiak 2002, s. 52-53.
} 


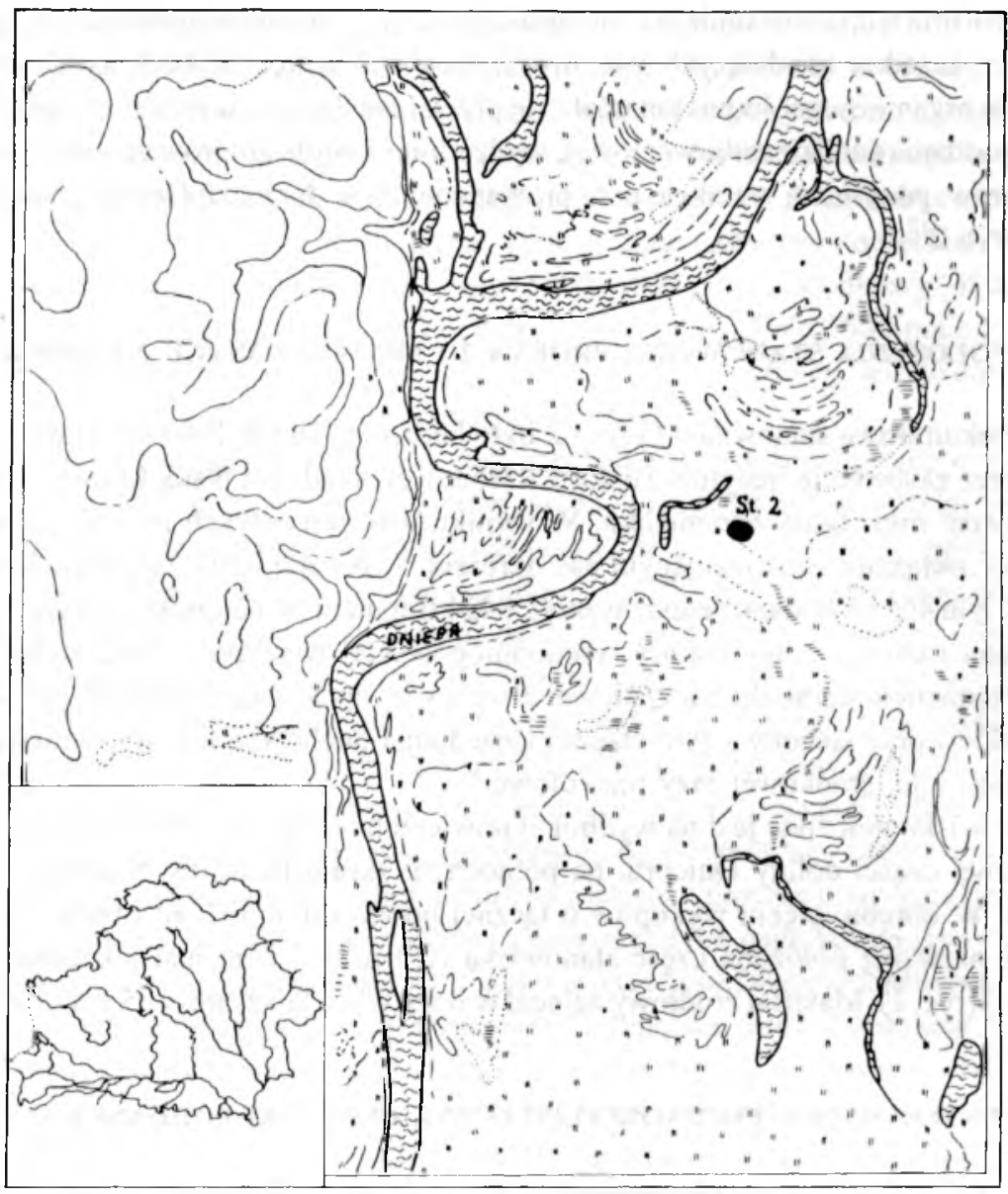

Ryc. 1. Prorva, rejon rogaczowski, stan. 2. Położenie stanowiska (rys. M. Gaździk)

Fig. 1. Prorva, site 2, the Rogaczów region. Site location (by M. Gaździk)

mieszana). Powierzchnia zewnętrzna pofałdowana, gładka, bez widocznego na powierzchni tłucznia. Powierzchnia wewnętrzna z wyraźnym nieregularnym ,przeczesywaniem”, wykonanym grzebykiem lub „zębatym stempelkiem”. Grubość ścianki wynosiła $9 \mathrm{~mm}$. Na tej podstawie omawiana ceramika może być wiązana dość jednoznacznie z III etapem rozwoju struktur dniepro-donieckich na Białorusi.

Próba Ki-9282 stanowi część brzuśca ostrodennego garnka, wykonanego z gliny schudzonej znaczną ilością domieszki różnobarwnego tłucznia kamiennego, z dodatkiem piasku oraz szczątków roślinnych. Fragment ma grubość $9 \mathrm{~mm}$, obie powierzchnie gładkie i lekko pofałdowane. Masa ceramiczna wykazuje słabe wymieszanie substancji, co powoduje, że przełam jest w tym przypadku gruzełkowaty. Badany fragment jest zdobiony na całej powierzchni odciskami klinowatego stempelka, które tworzą wątek dywano- 


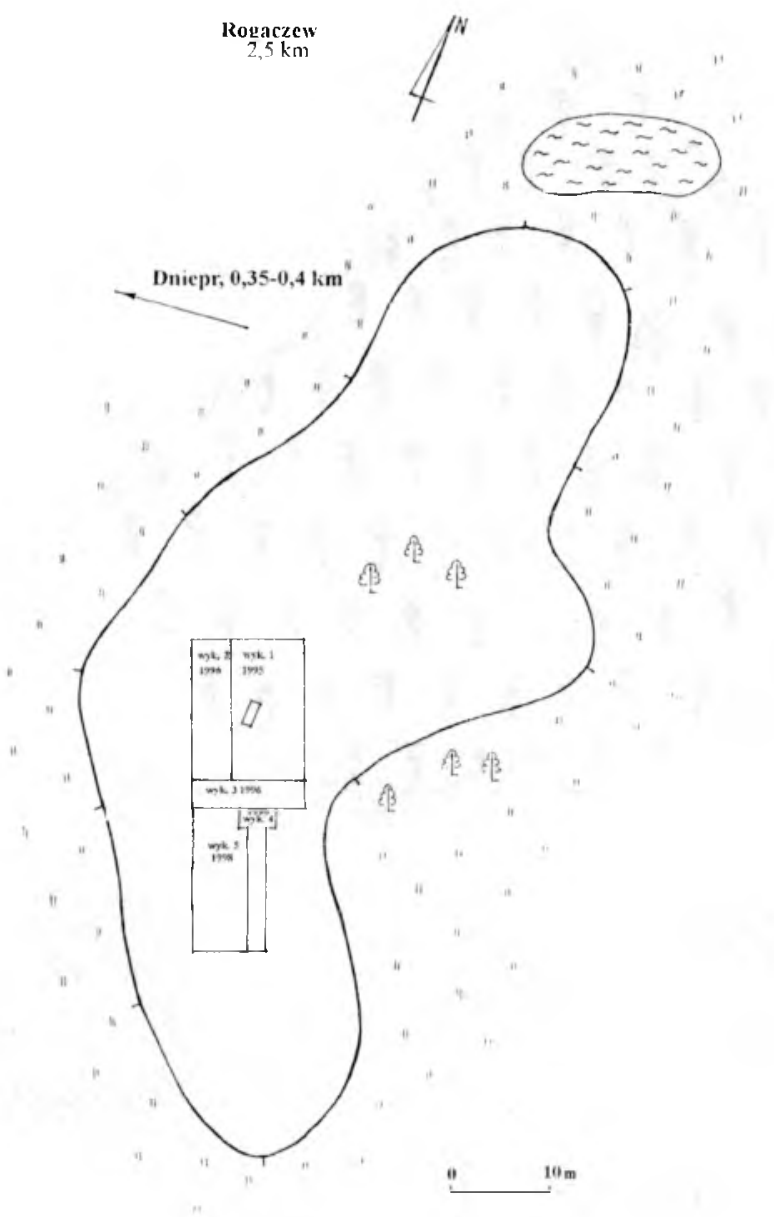

Ryc. 2. Prorva, rejon rogaczowski, stan. 2. Schemat rozplanowania wykopów (rys. I. Jaziepienko)

Fig. 2. Prorva, site 2, the Rogaczów region. Location of trenches (by I. Jaziepienko)

wy o układzie szachownicowym (ryc. 3:1). Na podstawie cech technostylistycznych fragment ten może być, z pewną ostrożnościa, zaliczany do etapu IV (trudność w jednoznacznym rozdzielaniu materiałów stykowych obu etapów).

Dwa fragmenty jednego naczynia, oznaczone jako próby Ki-9281 i Ki-9219, wykonane są w takiej samej technologii, jak omówiona powyżej próba Ki-9282, z tąjednak różnicą, że ze względu na silne zniszczenie powierzchni wewnętrznej nie udało się ustalić jej faktury. Omawiane fragmenty zdobione są regularnym układem horyzontalnych linii, wykonanych z rzędów pionowych odcisków delikatnego, trójzębnego grzebyka, które rozdzielają strefy niezdobione (ryc. 3:2, 3:3). Omówiona ceramika reprezentuje IV etap rozwojowy.

Dwa pozostałe fragmenty naczyń, poddane wcześniejszej analizie (Ki-6590 i Ki-7519), wykonane są w technologii typowej dla późnych zespołów dniepro-donieckich (do- 

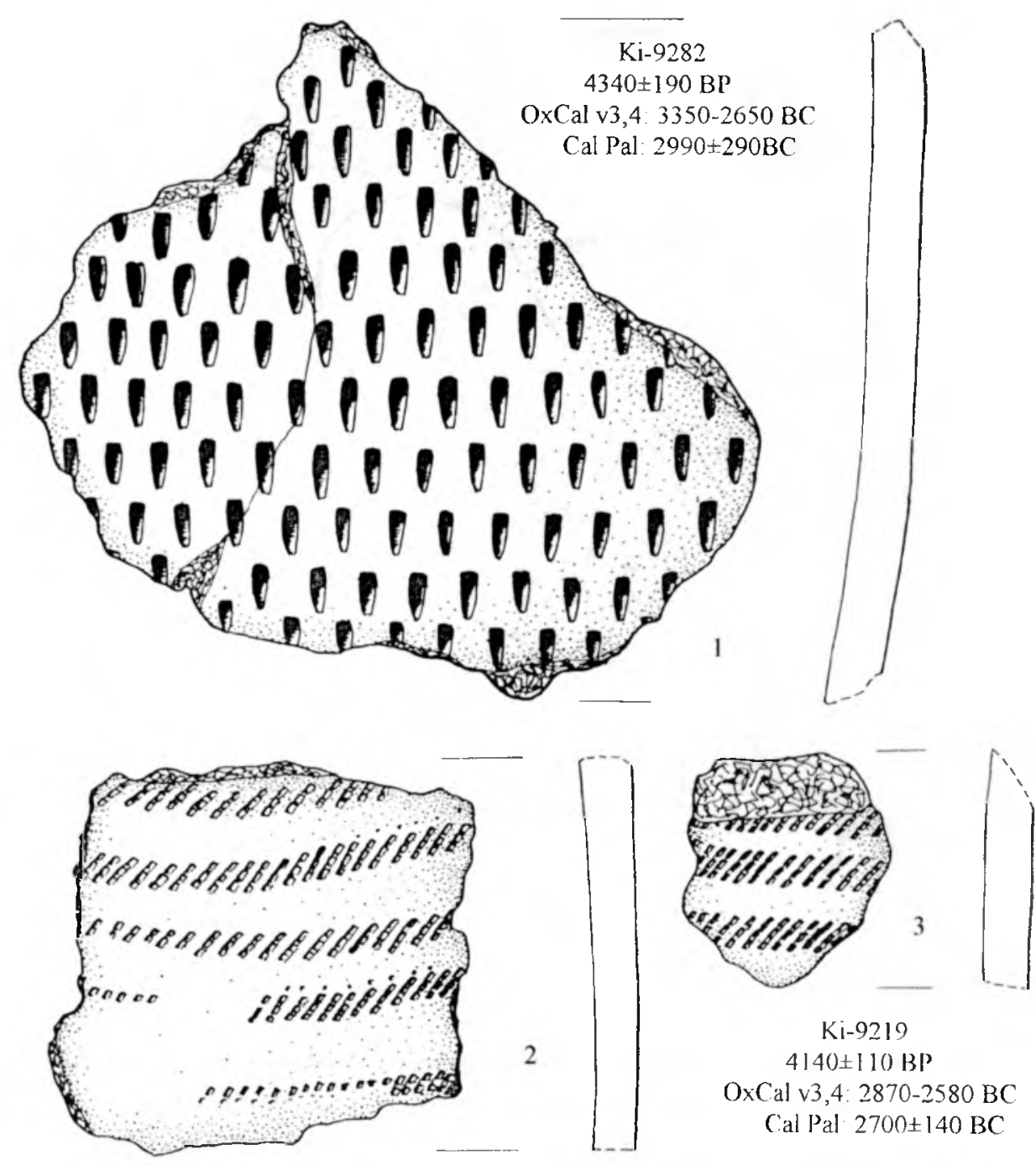

\section{Ki-928 I}

$4270 \pm 180 \mathrm{BP}$

OxCal v3,4:3300-2550 BC

$5 \mathrm{~cm}$

Cal Pal: $2910 \pm 280 \mathrm{BC}$

Ryc. 3. Prorva, rejon rogaczowski, stan. 2. Przedstawienie ceramiki dniepro-donieckiej, z której pozyskano oznaczenia radiowęglowe, wraz z ich wynikami (rys. M. Gaździk)

Fig. 3. Prorva, site 2, the Rogaczów region. Pottery of the Dnieper-Donetz culture used for radiocarbon dates (by M. Gaździk) 
mieszka tłucznia kamiennego i piasku, z mniejszą ilością materiału organicznego, przełam gruzełkowaty, wypał średni) i na tej podstawie oraz na podstawie analizy ornamentyki zostały już wcześniej zaliczone przez I. Jaziepienko do IV fazy rozwojowej grupy/ /kultury wschodniopoleskiej.

\section{KRYTYCZNE OMÓWIENIE WYNIKÓW OZNACZEŃ RADIOWĘGLOWYCH}

Analizy wymienionych wyżej próbek wykonano konwencjonalną metodą datowania radiowęglowego w laboratorium kijowskim. Ich wyniki skłaniają do podzielenia ogółu prób, pod względem jakości oznaczeń (ich dokładności), na dwie grupy.

Pierwsza $z$ nich obejmuje dwie próbki oddane do analizy w pierwszej kolejności

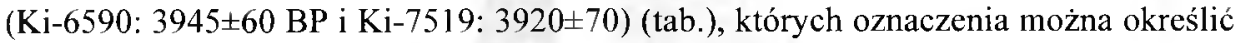
jako dobre czy nawet, zważając na niewielką ilość materiału do badan, bardzo dobre. Błąd w tych przypadkach nie przekracza \pm 70 lat, co pozwala na dość dokładne umiejscowienie obu datowanych fragmentów na osi czasu. Po kalibracji (Ki-6590: OxCal v3,42550-2320 BC, Cal Pal - 2430 \pm 100 BC; Ki-7519: OxCal v3,4-2490-2280 BC, Cal Pal - 2390 \pm 100 BC) (ryc. 4, 5; tab.), otrzymujemy dwie najpóźniejsze daty dla struktur dniepro-donieckich, które jednoznacznie potwierdzają, iż ugrupowania te w wersji schyłkowej (IV etap - który reprezentują omawiane materiały) przeżywały się prawie do schyłku III tys. p.n.e. (około $2300 / 2200$ p.n.e.) ${ }^{15}$.

Znacznie trudniejsza w interpretacji, ze względu na duży zakres błędów statystycznych $( \pm 110- \pm 190$ lat $)$, jest druga grupa oznaczeń, zawierająca wszystkie pozostałe próby (Ki-9280: $4520 \pm 190$ BP; Ki-9282: 4340 \pm 190 BP; Ki-9281: $4270 \pm 180$ BP; Ki-9219: $4140 \pm 110 \mathrm{BP}$; tab.). Zakres ten jest na tyle znaczący (co wynika w pewnej mierze $\mathrm{z}$ minimalnej ilości nadającego się do datowania materiału organicznego), że pozwala jedynie na dość ogólne umiejscowienie badanej ceramiki w strukturach chronologicznych. Dodatkowo należy nadmienić, iż w przypadku prób Ki-9281 i Ki-9219 mamy do czynienia z datowaniem dwóch fragmentów tego samego naczynia, którego wyniki różnią się o około 130 lat, a to wymusza dodatkową ostrożność w interpretacji otrzymanych wyników. Po kalibracji (Ki-9280: OxCal v3,4-3500-2900 BC; Cal Pal - 3220 \pm 250 BC; Ki-9282: OxCal v3,43350-2650 BC, Cal Pal - 2990 \pm 290 BC; Ki-9281: OxCal v3,4-3300-2550 BC, Cal Pal -

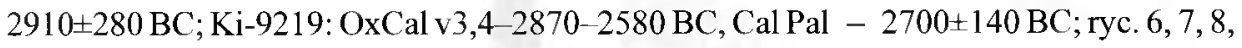
9; tab.) wyraźnie zaznacza się kolejny problem, związany z tym, że co najmniej 3 daty przypadają na odcinki kolejnych wypłaszczeń krzywej kalibracyjnej (może to thumaczyć wspomnianą rozbieżność datowań dwóch fragmentów jednego naczynia) - Ki-9280:3400-3100 BC; Ki-9282: 3100-2925 BC; Ki-9219: 2880-2600 BC ${ }^{16}$. Sytuacja taka, przy zwiększonych tym samym po kalibracji błędach statystycznych poszczególnych oznaczeń $( \pm 140$ \pm 290 ), zdecydowanie zawęża możliwości dalszego wnioskowania na ich podstawie.

\footnotetext{
${ }^{15} \mathrm{~J}$ aziepienk o $2000 \mathrm{a}$; J óźwiak 2002, s. 53.

${ }^{16}$ Czebreszuk, Szmyt 2001, tab. 2, fig. 4; Raetzel-Fabian 2001, s. 332-334.
} 


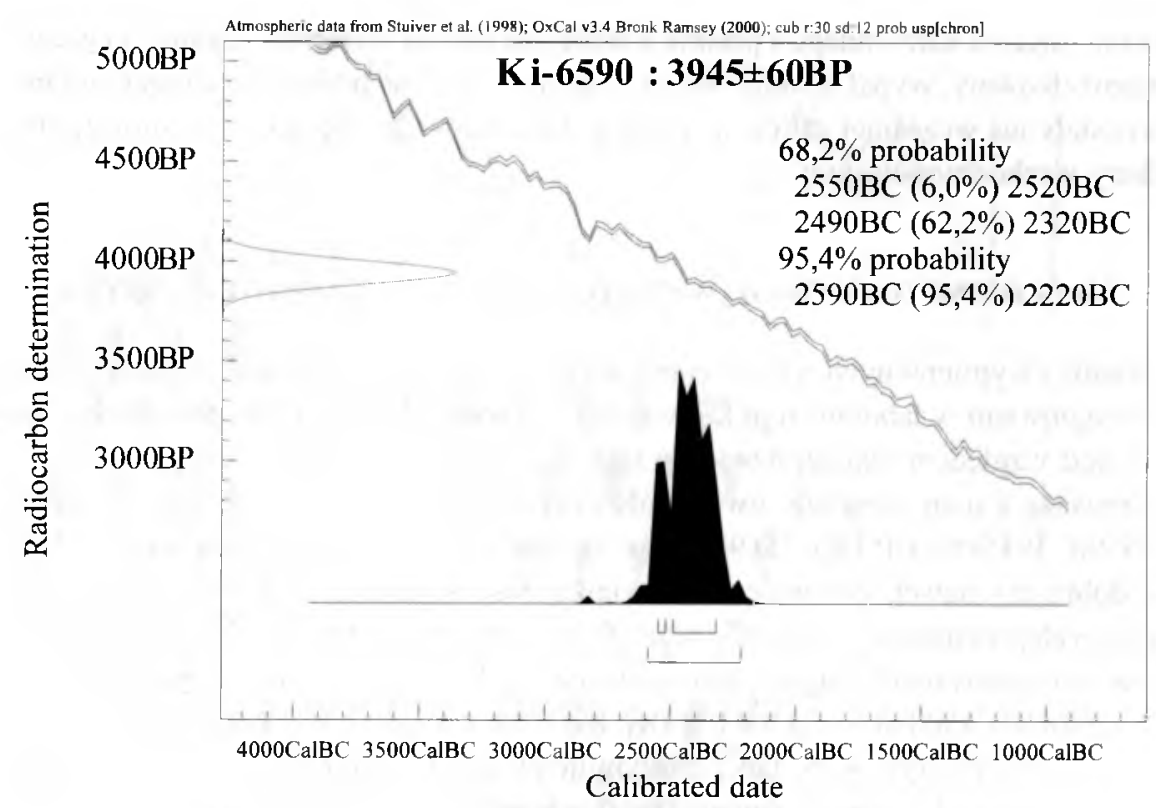

Ryc. 4. Prorva, rejon rogaczowski, stan. 2. Wykres kalibracji daty Ki-6590

Fig. 4. Prorva, site 2, the Rogaczów region. Calibration chart of the Ki-6590 date

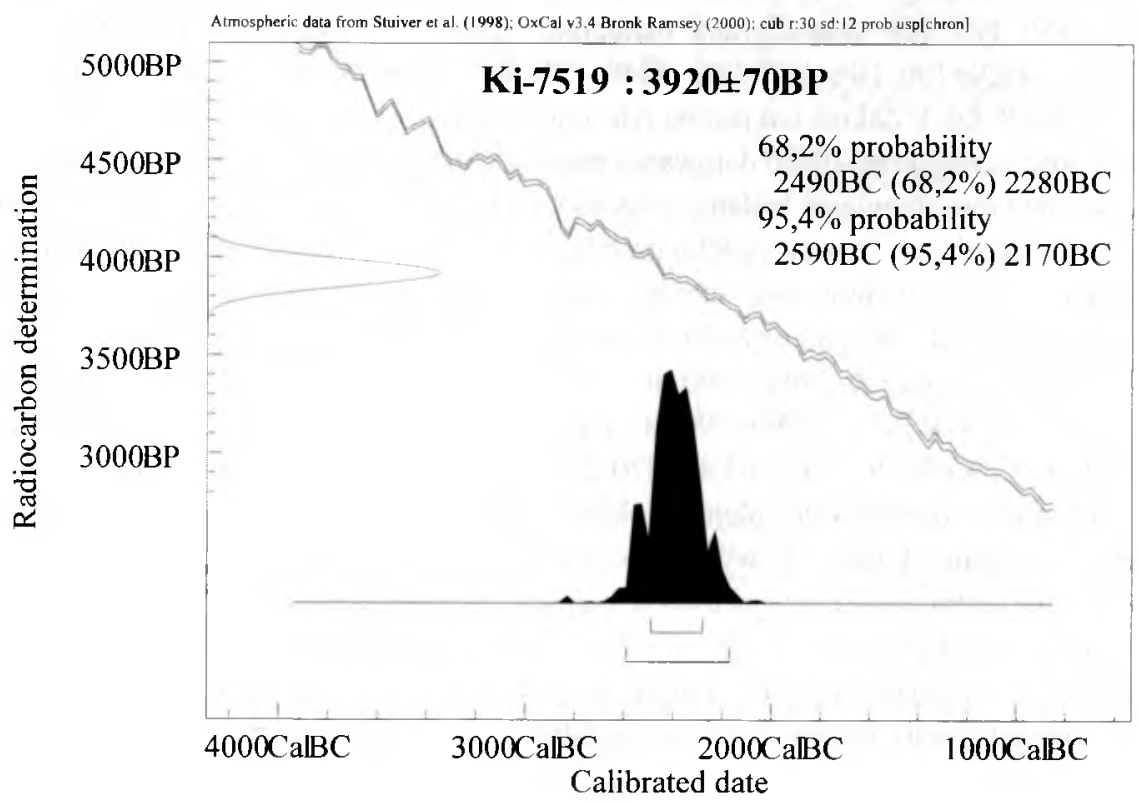

Ryc. 5. Prorva, rejon rogaczowski, stan. 2. Wykres kalibracji daty Ki-7519

Fig. 5. Prorva, site 2, the Rogaczów region. Calibration chart of the Ki-7519 date 


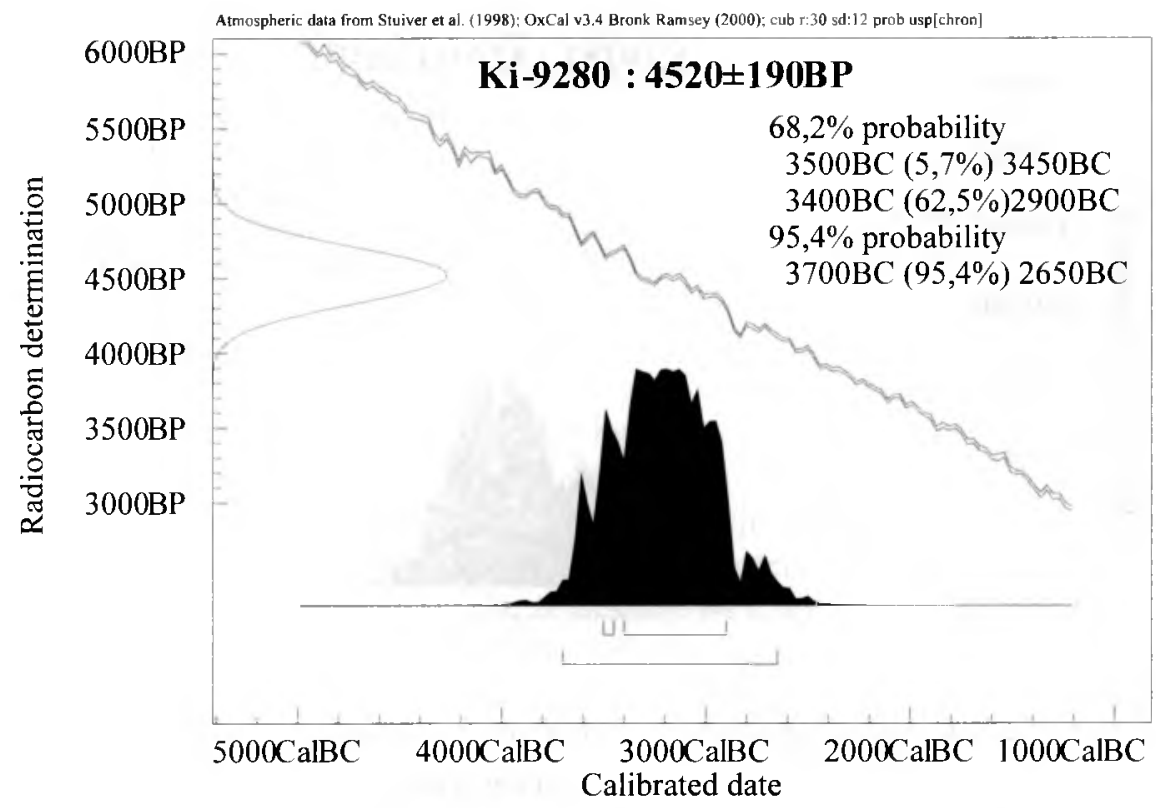

Ryc. 6. Prorva, rejon rogaczowski, stan. 2. Wykres kalibracji daty Ki-9280

Fig. 6. Prorva, site 2, the Rogaczów region. Calibration chart of the Ki-9280 date

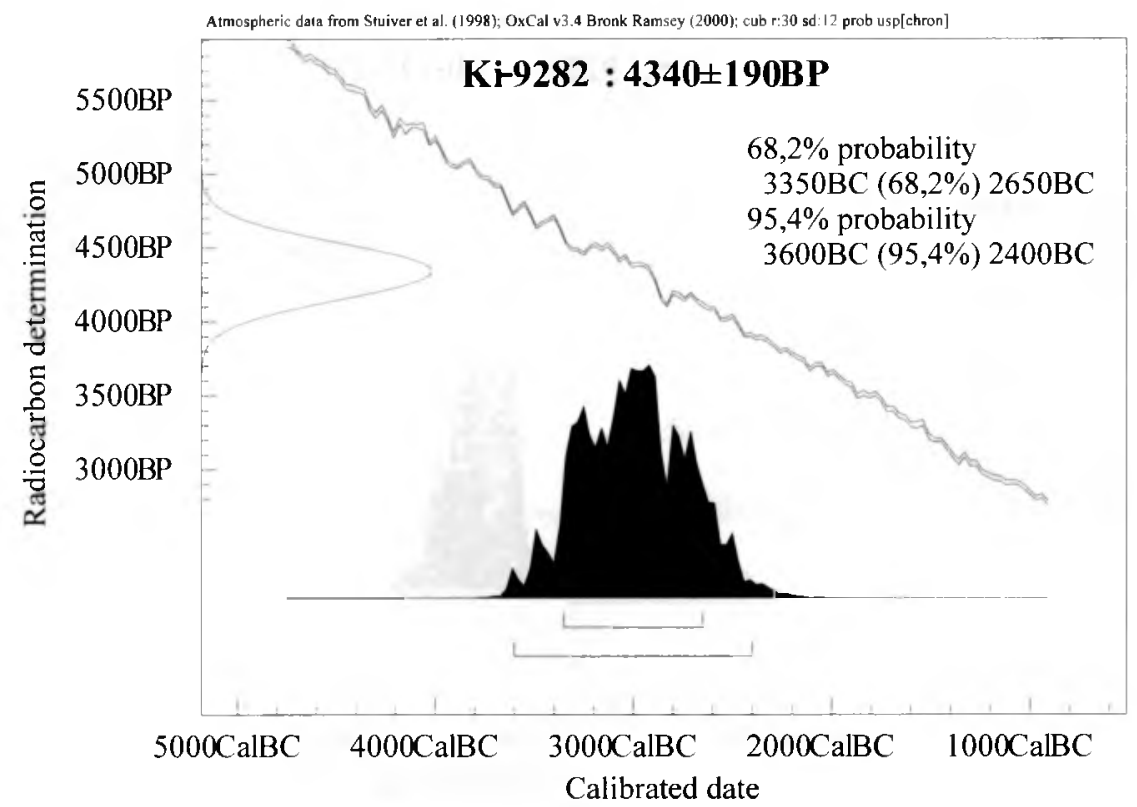

Ryc. 7. Prorva, rejon rogaczowski, stan. 2. Wykres kalibracji daty Ki-9282

Fig. 7. Prorva, site 2, the Rogaczów region. Calibration chart of the Ki-9282 date 


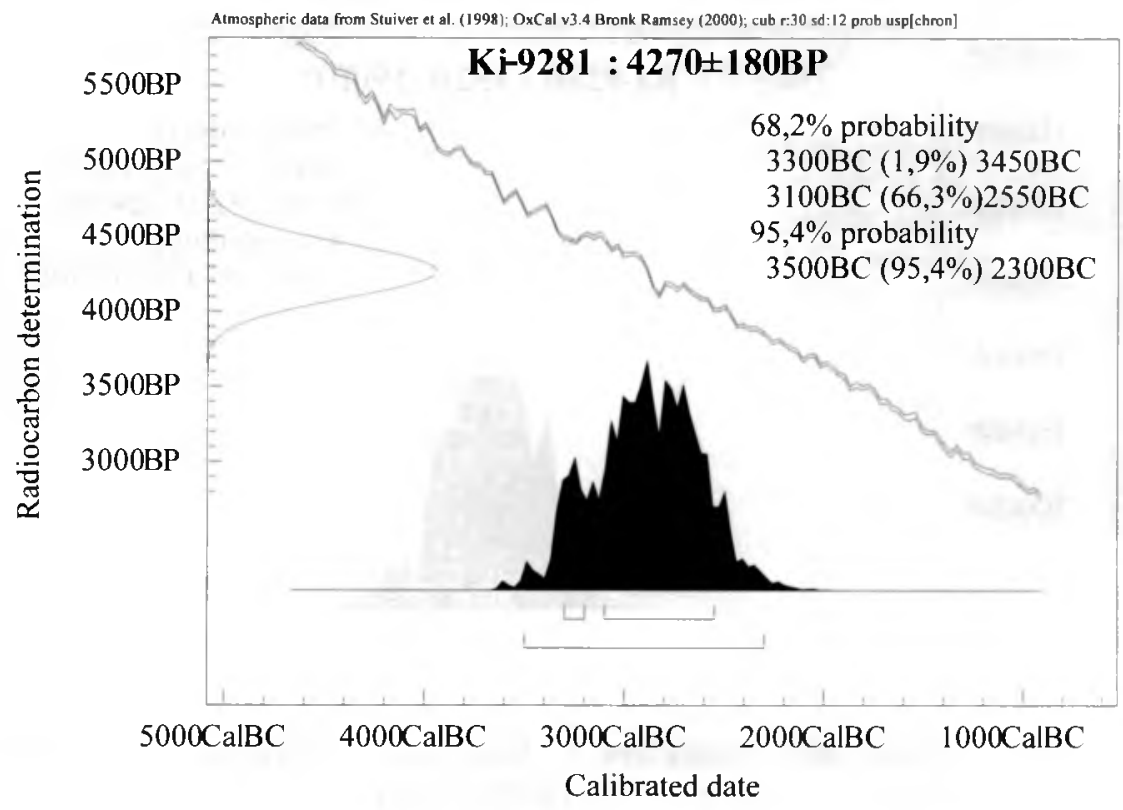

Ryc. 8. Prorva, rejon rogaczowski, stan. 2. Wykres kalibracji daty Ki-9281

Fig. 8. Prorva, site 2, the Rogaczów region. Calibration chart of the Ki-9281 date

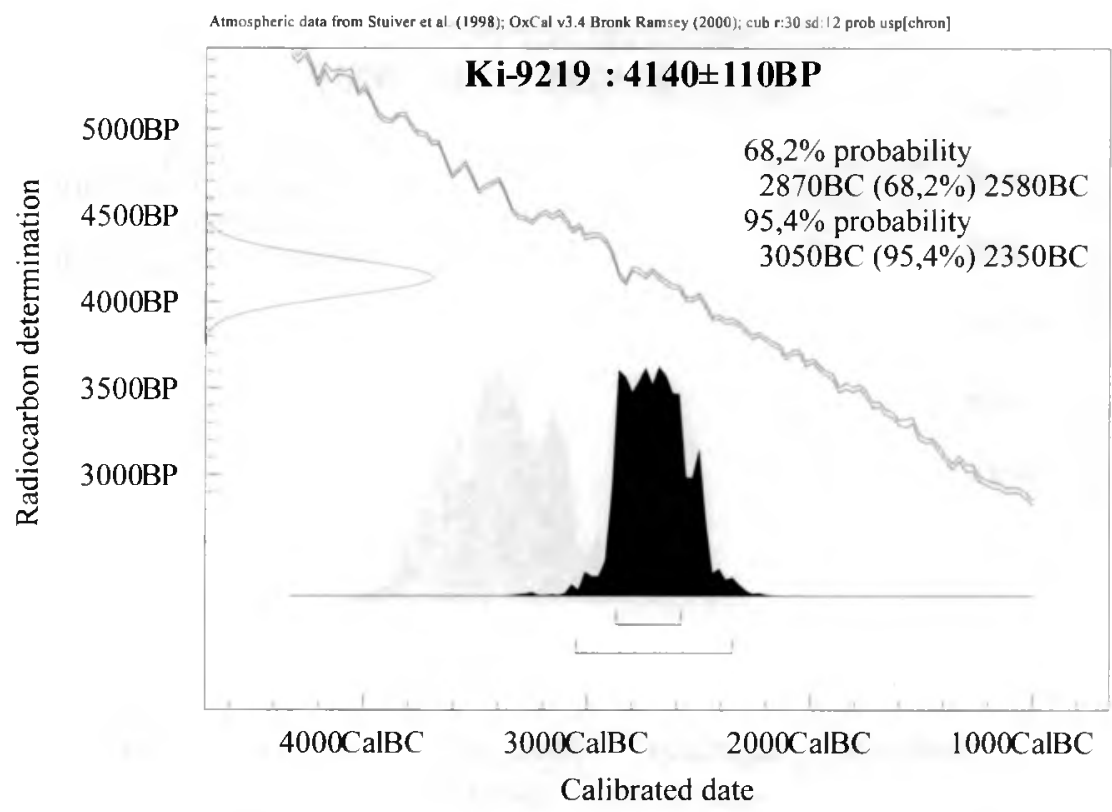

Ryc. 9. Prorva, rejon rogaczowski, stan. 2. Wykres kalibracji daty Ki-9219

Fig. 9. Prorva, site 2, the Rogaczów region. Calibration chart of the Ki-9219 date 
W przypadku wspomnianych wyżej dwóch różnych oznaczeń dla jednego naczynia zdecydowaliśmy się na wykonanie wspólnej kalibracji obu dat, w celu otrzymania wartości uśrednionej, która w tym przypadku mieści się w zakresie: OxCal v3,4-2900-4450 BC; Cal Pal - 3020-2570 BC (ryc. 10; tab.).

Ogół wartości otrzymanych w wyniku przeprowadzonych procedur pozwala na przyjęcie, z dużą ostrożnością, jako prawdopodobnego, następującego ciągu chronologicznego. Najstarsza data wiąże się z ceramiką reprezentującą zarówno w technologii, jak i stylistyce III etap rozwoju struktur dniepro-donieckich (ryc. 3, 11, 12). Pozostałe dwie (w tym jedna uśredniona dla dwóch fragmentów) pochodzą z naczyń, które - z punktu widzenia technologii i ornamentyki - można by zaliczać do IV lub ewentualnie schyłku III etapu (ryc. 3, 12,13). I właśnie w tym przypadku pozyskane datowania są najmniej przydatne analitycznie, gdyż ich szerokie zakresy, obejmujące w zasadzie czas trwania części obu etapów, przy owej możliwej niejednoznaczności technostylistycznej ceramiki (choć należy jednak wyraźnie wskazać, że znacznie bardziej wiarygodne wydaje się ich wiązanie z IV etapem), nie pozwalają na rozstrzygnięcie podjętej kwestii (ryc. 11). Z bardzo dużą rezerwą można by się pokusić o wskazanie dwóch wykluczających się hipotez: pierwszej - iż pod względem oznaczenia chronologicznego ceramika z próby Ki-9282 ciąży bardziej ku III etapowi, a naczynie datowane próbami Ki-9281 i Ki-9219 ku etapowi IV oraz drugiej - wskazującej na łączność obu fragmentów i zaliczenie ich do etapu IV, który tym samym byłby datowany bardzo wcześnie. Niestety, hipotezy te należy traktować bardzo ostrożnie, gdyż ogólny brak szerszych serii oznaczeń radiowęglowych dla obu etapów uniemożliwia ostateczne wyznaczenie ich ram chronologicznych oraz długości ewentualnego synchronicznego okresu rozwoju obu etapów. Także analiza rozrzutu przestrzennego wszystkich datowanych próbek nie pozwala na jednoznaczne rozstrzygnięcie ostatniej z podjętych tu kwestii (ryc. 14). O ile w przypadku skrajnych oznaczeń wyraźnie widać przestrzenną rozdzielność (bliskość ceramiki najmłodszej oraz

Atmospheric data from Stuiver et al. ( 1998); OxCal v3.4 Bronk Rarnsey (2000); cub r:30 sd:12 prob usp[chron]

Sum Daty z jednej skorupy

ki $-92194140 \pm 110 B P$

ki-9281 $4270 \pm 180 \mathrm{BP}$

Sum Daty z jednej skorupy

$6000 \mathrm{CalBC} \quad 5000 \mathrm{CalBC} \quad 4000 \mathrm{CalBC} \quad 3000 \mathrm{CalBC} 2000 \mathrm{CalBC} \quad 1000 \mathrm{CalBC}$ Calibrated date

Ryc. 10. Prorva, rejon rogaczowski, stan. 2. Suma kalibracji dat pochodzących z dwóch fragmentów tego samego naczynia

Fig. 10. Prorva, site 2, the Rogaczów region. Summary of calibrated dates from two fragments of the same clay vessel 
Atmospheric data from Stuiver et al. (1998); OxCal v3.4 Bronk Ramsey (2000); cub r:30 sd:12 prob usp/chron]

\section{Sum Suma wszystkich dat ze stan. Prorva 2}

Ki $-9280 \quad 4520 \pm 190 \mathrm{BP}$

Ki-9282 4340土190BP

$\mathrm{Ki}-92814270 \pm 180 \mathrm{BP}$

$\mathrm{Ki}-92194140 \pm 110 \mathrm{BP}$

Ki-6590 $3945 \pm 60 \mathrm{BP}$

$\mathrm{Ki}-75193920 \pm 70 \mathrm{BP}$

Sum Suma wszystkich dat ze stan. Promono

\section{$6000 \mathrm{CalBC} 5000 \mathrm{CalBC} 4000 \mathrm{CalBC} 3000 \mathrm{CalBC} 2000 \mathrm{CalBC} 1000 \mathrm{CalBC}$ Calibrated date}

Ryc. 11. Prorva, rejon rogaczowski, stan. 2. Suma wszystkich dat wspólnoty dniepro-donieckiej

Fig. 11. Prorva, site 2, the Rogaczów region. Summary of all radiocarbon dates from the Dnieper-Donetz culture

Tabela

Prorva, rejon rogaczowski, stan. 2. Zestawienie oznaczeń radiowęglowych dla kultury dniepro-donieckiej wraz z ich kalibracjami

\begin{tabular}{|c|c|c|c|c|c|}
\hline \multirow{2}{*}{$\begin{array}{l}\text { Symbol i numer } \\
\text { próby }\end{array}$} & \multirow{2}{*}{$\begin{array}{c}\text { Daty } \\
\text { niekalibrowane } \\
\text { (BP) }\end{array}$} & \multicolumn{2}{|c|}{ Daty kalibrowane (BC) } & \multirow{2}{*}{$\begin{array}{c}\text { Datowany } \\
\text { materiał }\end{array}$} & \multirow[b]{2}{*}{ Uwagi } \\
\hline & & $\begin{array}{c}\text { OxCal v3,4 } \\
(68,2 \%)\end{array}$ & Cal Pal & & \\
\hline $\mathrm{Ki}-9280$ & $4520 \pm 190$ & $3500-2900$ & $3220 \pm 250$ & $\begin{array}{c}\text { nagar } \\
\text { na ceramice }\end{array}$ & $\begin{array}{l}\text { fragment } \\
\text { nieornamentowany }\end{array}$ \\
\hline Ki-9282 & $4340 \pm 190$ & $3350-2650$ & $2990 \pm 290$ & $\begin{array}{c}\text { nagar } \\
\text { na ceramice }\end{array}$ & - \\
\hline $\mathrm{Ki}-9281^{* *}$ & $4270 \pm 180$ & $3300-2550$ & $2910 \pm 280$ & $\begin{array}{c}\text { nagar } \\
\text { na ceramice }\end{array}$ & \multirow{2}{*}{$\begin{array}{c}\text { OxCal v3,4 } \\
2900-2450^{*} \\
\text { Cal Pal } \\
3020-2570^{*}\end{array}$} \\
\hline $\mathrm{Ki}-9219^{* *}$ & $4140 \pm 110$ & $2870-2580$ & $2700 \pm 140$ & $\begin{array}{c}\text { nagar } \\
\text { na ceramice }\end{array}$ & \\
\hline $\mathrm{Ki}-6590 * * *$ & $3945 \pm 60$ & $2550-2320$ & $2430 \pm 100$ & $\begin{array}{c}\text { nagar } \\
\text { na ceramice }\end{array}$ & - \\
\hline $\mathrm{Ki}-7519^{* * *}$ & $3920 \pm 70$ & $2490-2280$ & $2390 \pm 100$ & $\begin{array}{c}\text { nagar } \\
\text { na ceramice }\end{array}$ & - \\
\hline
\end{tabular}

* Datowanie uśrednione, na poziomie $68,2 \%$ prawdopodobieństwa (OxCal v3,4) i 68\% prawdopodobieństwa (Cal Pal); ** daty dwóch fragmentów tego samego naczynia; *** daty wykonane wcześniej przez I. Jaziepienko. 

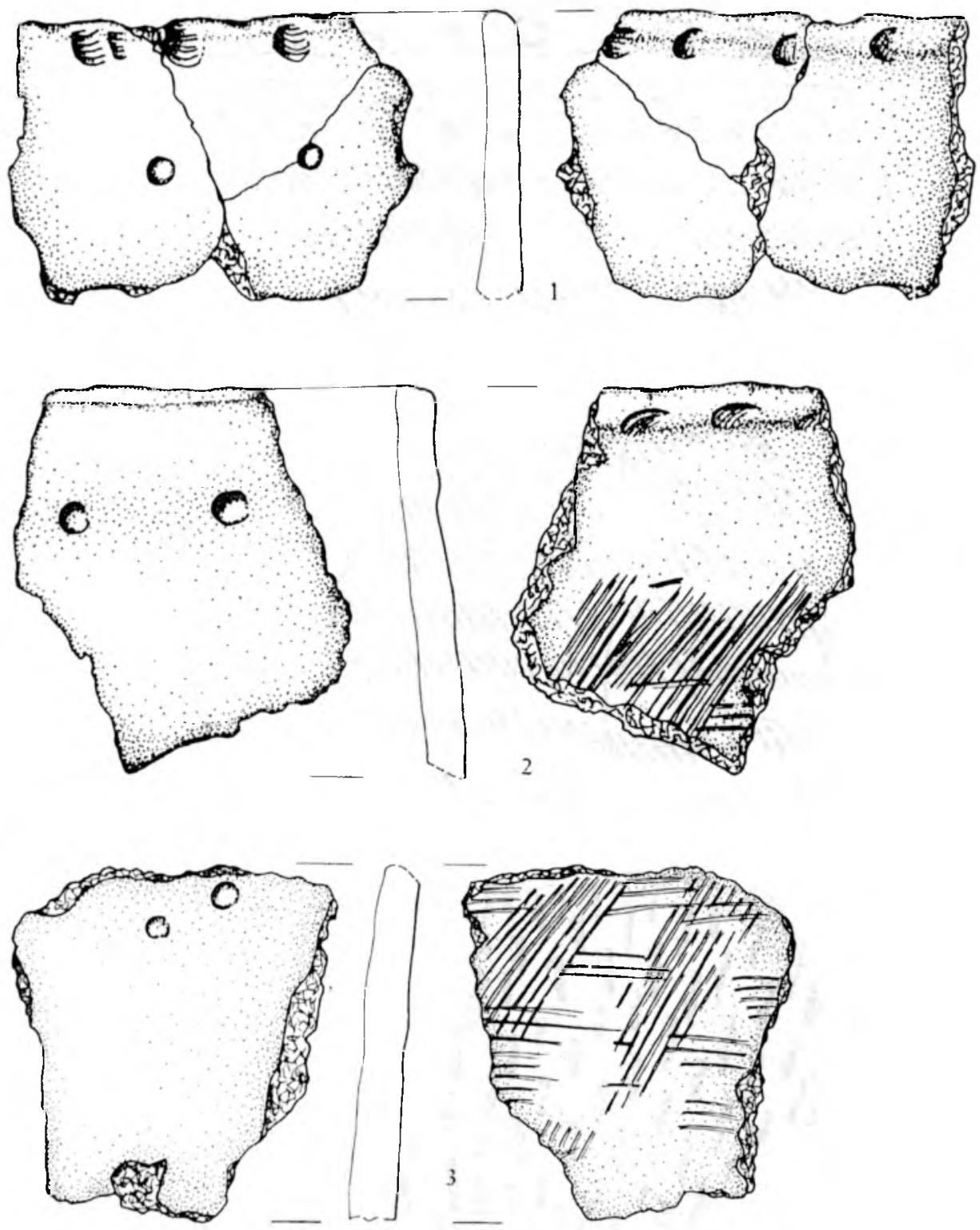

0 $5 \mathrm{~cm}$

Ryc. 12. Prorva, rejon rogaczowski, stan. 2. Wybór ceramiki dniepro-donieckiej z III etapu rozwoju; materiał zbieżny z datowanym (rys. M. Gaździk)

Fig. 12. Prorva, site 2, the Rogaczów region. Selection of the Dnieper-Donetz culture pottery from phase III (by M. Gaździk) 


\section{CQOCOCO}
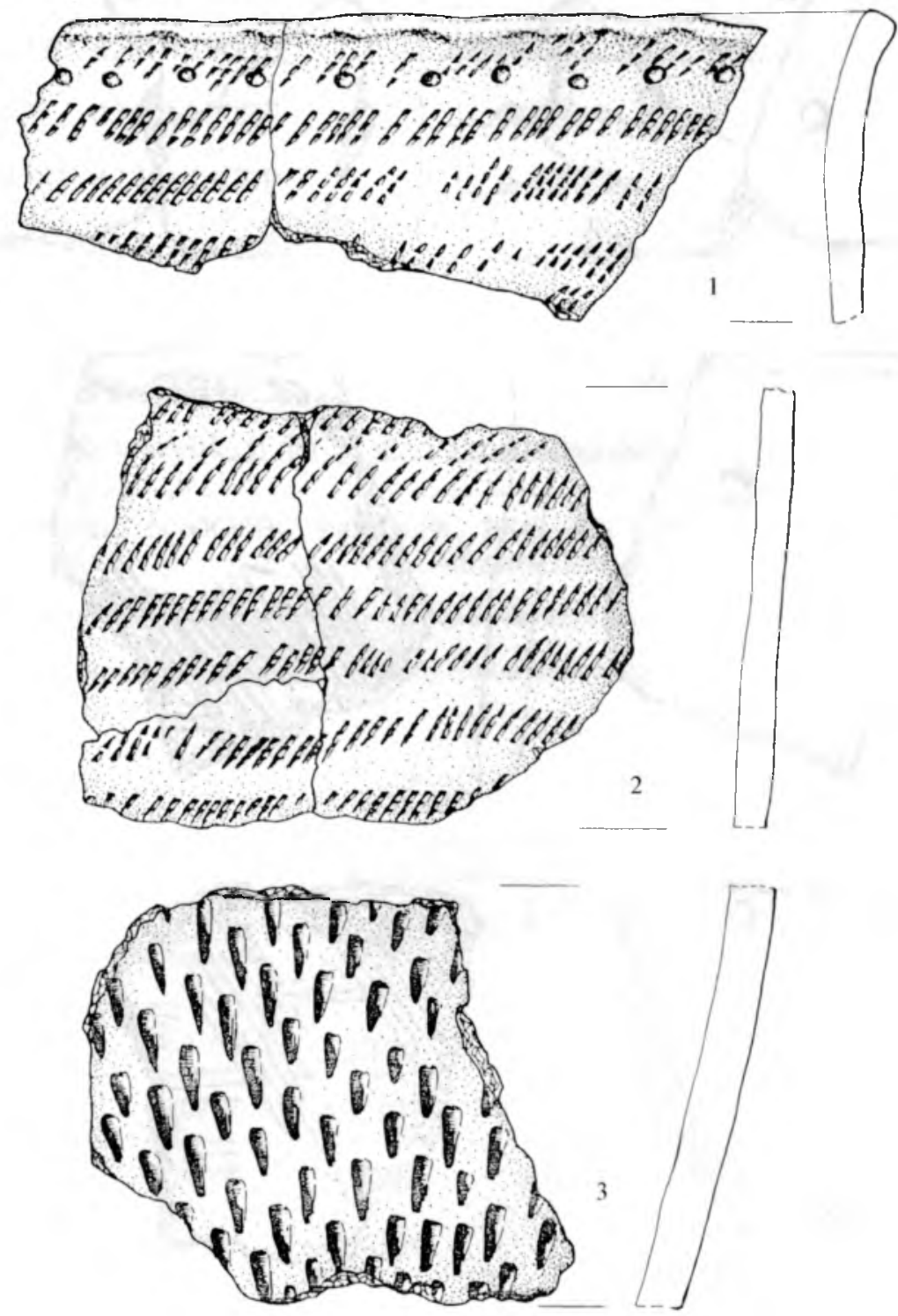

$\underbrace{0} 5 \mathrm{~cm}$

Ryc. 13. Prorva, rejon rogaczowski, stan. 2. Wybór ceramiki dniepro-donieckiej z IV etapu rozwoju; materiał zbieżny $\mathrm{z}$ datowanym (rys. M. Gaździk)

Fig. 13. Prorva, site 2, the Rogaczów region. Selection of the Dnieper-Donetz culture pottery from phase IV (by M. Gaździk) 


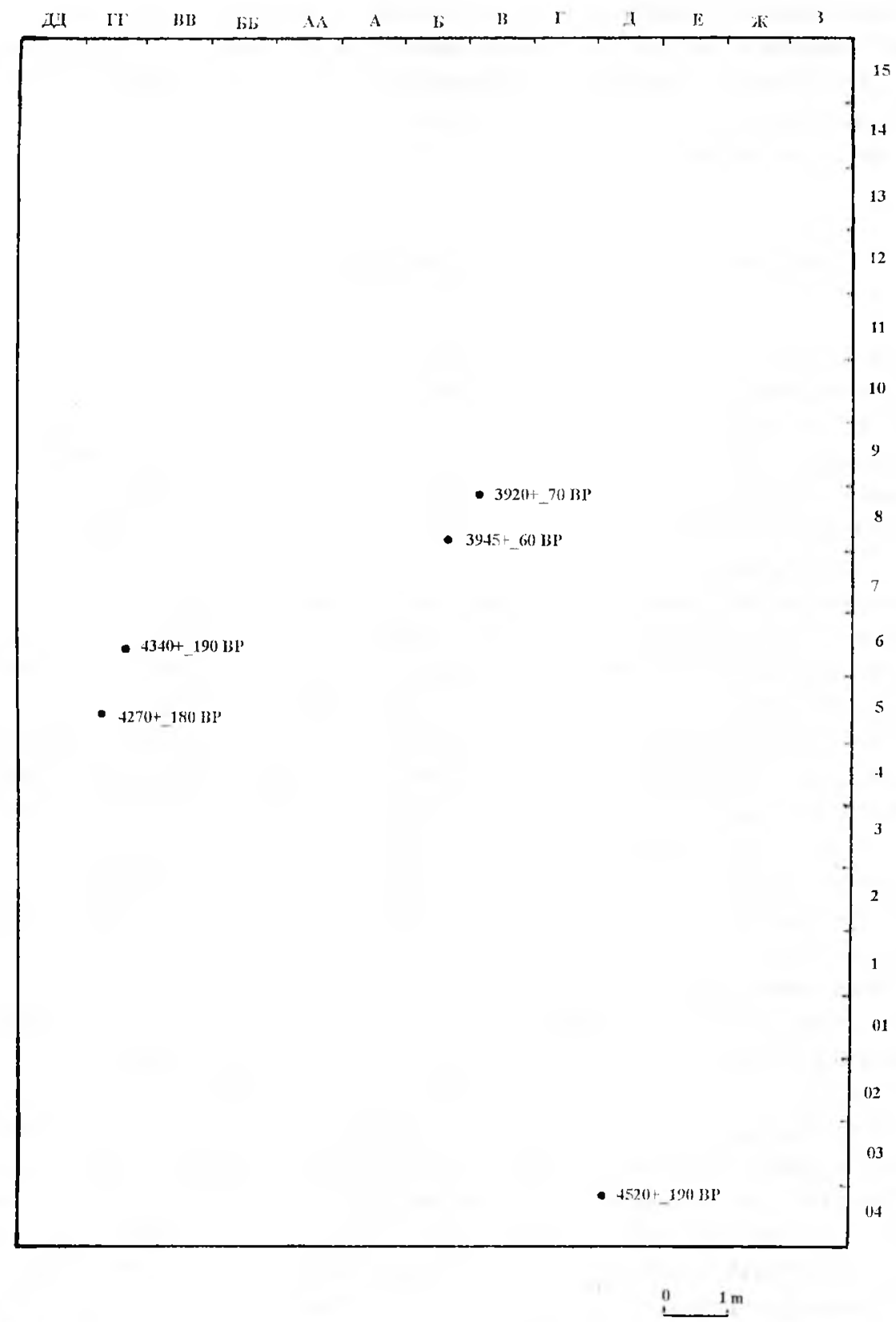

Ryc. 14. Prorva, rejon rogaczowski, stan. 2. Rozmieszczenie datowanych fragmentów ceramiki w obrębie wykopów (rys. I. Jaziepienko)

Fig. 14. Prorva, site 2, the Rogaczów region. Distribution of the dated pottery fragments in trenches (by I. Jaziepienko) 
wyraźne oddalenie ceramiki najstarszej), o tyle obie sporne daty dotyczą ceramiki, która została odkryta w bezpośredniej swojej bliskości oraz w oddaleniu od pozostałych (ryc. 14). Taka sytuacja może jedynie wskazywać na większe prawdopodobieństwo drugiej z przedstawionych hipotez (reprezentowanie przez oba fragmenty jednego, IV etapu), ale nie rozstrzyga przedmiotowej kwestii ostatecznie.

\section{CHRONOLOGIA PÓŹNYCH FAZ WSPÓLNOTY DNIEPRO-DONIECKIEJ NA BIALORUSI - ZARYS WNIOSKÓW}

Jak wynika z przedstawionej wyżej analizy, pozyskane datowania C 14 materiałów dniepro-donieckich z obszaru Białorusi, mimo dość małej w kilku przypadkach precyzyjności, pozwalają na wysunięcie pewnych generalnych wniosków dotyczących ram chronologicznych rozwoju późnych struktur tej wspólnoty. Na ich podstawie możemy potwierdzić dotychczasowe sytuowanie początków rozwoju późnych struktur dniepro-donieckich około 3500 lat p.n.e. (początek rozwoju stylistyk wiązanych z etapem III). Znacznie bardziej problematyczne i trudne do rozstrzygnięcia kwestie wiążą się z okresem przejścia od stylistyki etapu III do IV. Naszym zdaniem, choć jest to tylko hipoteza, należy zakładać istnienie wyraźnie zaznaczonego okresu przejściowego pomiędzy oboma etapami (ich częściową współczesność), wykluczającego cegiełkowy schemat rozwoju struktur dniepro-donieckich (co jest zresztą zgodne z ogólnoeuropejskim trendem we współczesnej refleksji prahistorycznej, polegającym na bardziej dynamicznym ujmowaniu zjawisk pradziejowych). Takie postawienie problemu pozwala zakładać, iż rysująca się - bardzo ogólna - tendencja do postarzania początków etapu IV, na co moga wskazywać otrzymane daty, jest wysoce prawdopodobna. Stąd początki tego etapu można, z dużą ostrożnością, umiejscawiać około $3100 / 3000$ p.n.e., co przy założeniu trwania stylistyki wiązanej z III etapem do schyłku IV tys. p.n.e. (około 3000 p.n.e.), wskazuje na istnienie wspomnianej wyżej częściowej współczesności obu etapów.

Zdecydowanie najmniej wątpliwości budzi ustalenie momentu zaniku wspólnoty dniepro-donieckiej (koniec etapu IV). Z uzyskanych datowań wyraźnie wynika, iż schyłek omawianych zjawisk należy na tym obszarze datować co najmniej na lata około 2300/2200 p.n.e., co w istotny sposób wydłuża jego chronologię.

Takie ramy chronologiczne IV etapu powoduja, że osadnictwo dniepro-donieckie z nim związane współegzystuje przez pewien czas z rozwijającymi się w tym samym okresie spolecznościami kultury środkowodnieprzańskiej i kultury górnodnieprzańskiej oraz z sąsiednimi ugrupowaniami kręgu kultury niemeńskiej - w jej klasycznej postaci (tzw. typ Dobryj Bor). Schemat ten potwierdzają dodatkowo, wskazywane już wcześniej w literaturze przedmiotu, wpływy stylistyczne wspomnianych kultur, rejestrowane w ceramice dniepro-donieckiej tego etapu.

Reasumując należy podkreślić wyjątkową wagę prologu procesu sukcesywnego datowania radiowęglowego materiałów dniepro-donieckich z terenu Białorusi, zaznaczając jego ciągle inicjalną fazę. Należy jednak sądzić, że dalsze prowadzone na tym polu bada- 
nia pozwolą w niedługim czasie uzyskać większe serie dokładnych oznaczeń radiowęglowych, które w konsekwencji umożliwią ustalenie szczegółowej chronologii wewnętrznej omawianych zjawisk. Z tej perspektywy niniejszy artykuł należy traktować jako zaczyn przyszłych, znacznie szerszych studiów.

\section{BIBLIOGRAFIA}

Archieotogia

1985 Archieologia Ukrainskoj SSSR, t. 1: Piervobytnaja Archieologia, Kiev.

Czebreszuk J., Szmyt M.

2001 The 3rd Millenium BC in Kujawy in the Light of C14 Dates, (w:) The Absolute Chronology of Central Europe 3000-2000 BC (ed. J. Czebreszuk, J. Müller), Poznań - Bamberg - Rahden, s. $177-208$.

Is ajenko V.F.

1978 Chronologija nieolita Juznoj Bielorussii, „Korotkije Soobszczienija” t. 153, s. 37-42.

1997 Dniepro-danieckaja kultura, (w:) Archieologija Bielarusi, t. 1. Kamienny i bronzovy viaki, Minsk, s. 127-144.

Jaziepienko I.

1994 Da pytania ab intierprietacyi materyalau nealityćnych pasieliszczau Bietoruskava Padniaprovia, „Gistaryczna-Archiolagiczny Sbornik” t. 3, s. 10-26.

1995 Matieriaty pasieliszcza va urocziszcy Sasonka i jago miesca u nealitie Vierchniava Padniaprovia, „Gistaryczna-Archiołagiczny Sbornik” t. 7, s. 60-82.

2000a Chronotogija nieoliticzieskich posielienij Bielorusskovo Podnieprovija, (w:) Chronologija nieolita Vostocznoj Europy (księga abstraktów), Petersburg, s. 79-81.

2000b Dniepro-danieckaja kultura u basiejnie vierchniga Dniapra, Starażytnasci Ragaciouszciny, Minsk - Ragaciau, s. 14-26.

Jóźwiak B.

2002 Spoleczności subneolityczne Niżu w międzyrzeczu Odry i Wisly, t. I i II, Poznań (maszynopis pracy doktorskiej w bibliotece Istytutu Prahistorii UAM w Poznaniu).

Kempisty E.

1973 Kultura ceramiki ,grzebykowo-dolkowej” na Mazowszu i Podlasiu, „Wiadomości Archeologiczne" t. 38, z. 1, s. 3-76.

Kryvalsevicz M.M., Kovaliuch N.M.

1999 Radiocarbon Dating of the Middle Dniepr culture from Belarus, „Baltic-Pontic Studies” vol. 7, s. $151-163$.

Raetzel-Fabian D.

2001 Revolution, Reformation, Epochenwechsel? Das Ende der Kollektivgrabsitte und der Übergang von der Wartberg- zur Einzelgrabkultur in Nordhessen und Westfalen, (w:) The Absolute Chronology of Central Europe 3000-2000 BC (ed. J. Czebreszuk, J. Müller), Poznań - Bamberg - Rahden, s. 319-336.

Telegin D.J.

1961 K voprosu o dniepro-donieckoj nieoliticzeskoj kulturie, „Sovietska Archieołogija” z. 4, s. 26-40.

1967 Istoria pliemien dniepro-donieckoj kultury ( $V$-III tys. d.n.e.). Avtoreferat dissertacji na soiskanie uczonoj stiepieni doktora istoriczeskich nauk, Kiev.

1968 Dniepro-donieckaja kultura, Kiev.

1999 Dniepr jako pogranicze zachodnioeuropejskich (balkańsko centralnoeuropejskich) $i$ wschodnioeuropejskich wspólnot etniczno-kulturowych w neolicie i eneolicie (V-III tysiqclecia p.n.e.), „Folia Praehistorica Posnaniensia" t. IX, s. 9-40. 
2000 Ob osnovnych liniach etnokulturnovo razvitia neo-eneoliticzeskovo vriemieni jugozapada Vostocznoj Europy i ich chronologija, (w:) Chronologija nieolita Vostocznoj Europy (księga abstraktów), Petersburg, s. 79-81.

Telegin D.J., Titova E.N.

1998 Posielienia dniepro-donieckoj etnokulturnoj obszcznosti epochi neolita, Kiev.

\section{CHRONOLOGY OF THE LATE PHASES OF THE DNIEPER-DONETZ CULTURE IN BYELORUSSIA IN THE LIGHT OF THE NEWEST RADIOCARBON DATES FROM PRORVA, SITE 2, THE ROGACZÓW REGION}

\section{S u m mary}

The Dnieper-Donetz culture/community, which was defined at the turn of the sixties of the $20^{\text {th }}$ century, is located in larger part of Ukraine and in southern part of Byelorussia. According to the newest studies, it is believed to get formed in the Dnieper River Side and Polissya regions and the forest-steppe part of the right bank of the Dnieper river. It was created from the local Mesolithic groups, who remaining under the influence of the Bug-Dniester culture, adopted a pottery manufacture and to less extent a production of the new flint tools. The Dnieper-Donetz culture could be divided into three chronological phases: (1) Early (5500-4800 BC), (2) Middle, in which a number of local groups of this culture develops ( $4800-3800 \mathrm{BC}$, or even $3500 \mathrm{BC}$ at the Prypetz basin), and (3) Late (3800/3500 $\mathrm{BC}-3000 \mathrm{BC}$, or even, as previously thought, until the middle of the second millenium $\mathrm{BC}$ in Byelorussia).

The Dnieper-Donetz culture exists in all three phases in the discussed territory, while though the Late phase in Ukraine corresponds with phases III and IV in Byelorussia.

A serious shortcoming of the chronological studies of the Dnieper-Donetz culture at this territory was a complete lack of radiocarbon dates. It made a detailed analysis of internal development of this phenomenon impossible. This deadlock has been broken only recently thanks to excavations of a dune site at Prorva 2 in the Rogaczów region on the right bank of the Dnieper river, conducted by Igor Jaziepienko in the years 1994-1996 and 1998. The excavations brought about fragments of clay vessels with organic intrusions, which proved to be suitable for radiocarbon dating. As a result, six pottery fragments, stylistically belonging to phases III and IV of the Dnieper-Donetz culture, have been dated in the Radiocarbon Laboratory of the Ukrainian Academy of Sciences in Kiev.

The radiocarbon dates (table 1) make possible to draw some important conclusions regarding the development of this culture in its later phases, despite considerable statistical errors caused by a minimal amount of the organic substance suitable for dating. According to the results, there is no doubt that disappearance of this culture is to be dated to the end of the third millenium BC (Ki-6590: OxCal v3,4-2550-2320 BC; Cal Pal $2430 \pm 100 \mathrm{BC}$ and Ki-7519: OxCal v3,4-2490-2280 BC; Cal Pal-2390 $\pm 100 \mathrm{BC}$ ). Besides, a synchronism of phase III (Ki-9280: OxCal v3,4-3500-2900 BC; Cal Pal-3220 $250 \mathrm{BC}$ ) and IV (Ki-9282: OcCal v3,4-3350$-2650 \mathrm{BC}$; Cal Pal $-2990 \pm 290 \mathrm{BC}$ and $\mathrm{Ki}-9281 / \mathrm{Ki}-9219$ - both dates from one vessel - OxCal v3,4-2900$-2450 \mathrm{BC}$; $\mathrm{Cal} \mathrm{Pal}-3020-2570 \mathrm{BC}$; it must be noted that all the pottery fragments stylistically are to be placed somewhere between phase III and IV, albeit closer to the latter) became apparent. Observed synchronism in the development of these two stylistics is a considerable novum in studies of the discussed phenomenon.

In conclusion, one has to stress an importance of the first radiocarbon dates of the 'IDnieper-Donetz' assemblages from Byelorussia, which are to begin a new phase in studies of these phenomena and become a foundation of modern research project based upon complex dating of a wide array of materials from the discussed culture. 